\title{
Photocatalytic oxidation for degradation of VOCs
}

\author{
Lin Lin ${ }^{1}$, Yuchao Chai ${ }^{2}$, Bin Zhao ${ }^{1}$, Wei Wei ${ }^{3}$, Dannong He ${ }^{1,2^{*}}$, Belin $\mathrm{He}^{4}$, Qunwei Tang ${ }^{4 *}$ \\ ${ }^{1}$ National Engineering Research Center for Nanotechnology, Shanghai, China \\ ${ }^{2}$ School of Material Science and Engineering, Shanghai Jiao Tong University, Shanghai, China \\ ${ }^{3}$ State Key Laboratory of Bioreactor Engineering, New World Institute of Biotechnology, East China University of Science and \\ Technology, Shanghai, China \\ ${ }^{4}$ Institute of Materials Science and Engineering, Ocean University of China, Qingdao, China \\ Email: ${ }^{\text {hdnbill@sh163.net, }}$, $\underline{\text { tangqunwei@ouc.edu.cn }}$
}

Received 15 September 2012; revised 14 October 2012; accepted 28 October 2012

\begin{abstract}
Volatile organic compounds (VOCs) are the major group of indoor air pollutants, which significantly impact indoor air quality (IAQ) and influence human health. Photocatalytic oxidation (PCO) is a cost-effective technology for VOCs removal, compared with adsorption, biofiltration, or thermal catalysis method. Development of active photocatalyst systems is crucial for the PCO reaction. In this paper, the catalyst systems for photocatalysis under UV and visible light were discussed and the kinetics of photocatalytic oxidation was presented in order that some key influencing factors (relative huminity, light intensity, initial contaminant concentration and mass of catalyst) had also been studied. In addition, the future research directions were also presented in this paper.
\end{abstract}

Keywords: Indoor VOCs; Photocatalytic Oxidation; Synergistic Photocatalysts; Titanium Dioxide

\section{INTRODUCTION}

In today's life, indoor air pollutions have drawn a global attention regarding the imporvment of indoor air quality (IAQ). Indoor air pollutants mainly include nitrogen oxides $\left(\mathrm{NO}_{\mathrm{x}}\right)$, carbon oxides $\left(\mathrm{CO}\right.$ and $\left.\mathrm{CO}_{2}\right)$, volatile organic compounds (VOCs) and particulates. Among the pollutions, VOCs are prominent representative indoor pollutants which commonly include trichloroethylene $\left(\mathrm{C}_{2} \mathrm{HCl}_{3}\right)$ [1], acetone $\left(\mathrm{C}_{3} \mathrm{H}_{6} \mathrm{O}\right)$, 1-butanol $\left(\mathrm{C}_{4} \mathrm{H}_{10} \mathrm{O}\right)$, butyraldehyde $\left(\mathrm{C}_{4} \mathrm{H}_{8} \mathrm{O}\right)$ [2], m-xylene $\left(\mathrm{C}_{8} \mathrm{H}_{10}\right)$ [2], 1,3-Butadiene $\left(\mathrm{C}_{4} \mathrm{H}_{6}\right)$ [3], toluene $\left(\mathrm{C}_{6} \mathrm{H}_{5} \mathrm{CH}_{3}\right)$ [3], and formaldehyde $\left(\mathrm{CH}_{2} \mathrm{O}\right)[2,3]$. VOCs are known to have longterm effects on humans and considered to be carcinogenic, mutagenic, or teratogenic [4-6]. Moreover, some VOCs emissions can contribute to the formation of urban smog and ozone, stratospheric ozone depletion and the greenhouse effect [7].

With the increasing concerns on the indoor air quality,

*Corresponding authors. the degradation of VOCs has easily become the main point of research efforts in today's scientific world. Three methods are commonly used to control the emission of VOCs, such as adsorption by activated carbon [8] which merely transfers pollutants from gaseous phase to solid phase instead of destroying them, biofiltration which is slow and no obvious effect, and thermal oxidation destruction [9-11] which requires high temperatures of $200^{\circ} \mathrm{C}-1200^{\circ} \mathrm{C}$ for efficient operation and expensive. Moreover, all these techniques have inherent limitations, and none of them is decisively cost-effective for gas stream with low to moderate concerntion and large numbers of compounds, as the recovery and reuse of the compounds is not economically feasible. Therefore, there is a great demand for a more cost-effective, more efficient and environmentally benign technology [9]. Photocatalytic oxidation (PCO) does not have the above mentioned problems and are cost-effective for treating low concerntion pollutions. PCO has received considerable attention regarding the removal of air pollutants during the last years $[12,13]$. It has been demonstrated that organics can be oxidized to harmless carbon dioxide, and water which makes PCO especially attractive for treating air indoor pollutants. Furthermore, PCO requires a low temperature and pressure, employs inexpensive semiconducting catalysts, and is suitable for the oxidation of a wide range of pollutants, both of organic and inorganic nature. Researchers have already focused on this promising technique and many beneficial advancements have been made in the field of VOCs [14-27].

Removal of VOCs from indoor air can be achieved using photocatalytic oxidation (PCO), an efficient, promising and cost-effective approach. This behavior is due to the employment of highly efficient photocatalysts. Development of active catalyst systems is crucial for this technology. $\mathrm{TiO}_{2}$ is the most popular photocatalyst currently employed due to the hydrophilic properties of $\mathrm{TiO}_{2}$ and its ability to degrade a wide range of inorganic and organic compounds under irradiation of UV or near UV-light [28-32].

In this work, the recent progress from various photo- 
catalyst systems for on PCO reaction under UV and visible light is summarized. The key factors influencing the catalytic behaviros and the kinetics will be discussed. The future research directions and a larger scale application of the technology will also be presented.

\section{MECHANISM OF PCO REACTION}

Figure 1 presents the schematic of photocatalytic oxidation using $\mathrm{TiO}_{2}$ as the photocatalyst. During the photocatalytic oxidation, the most important step of photoreaction is the formation of hole-electron pairs which need energy to overcome the band gap between the valence band (VB) and conduction band (CB) [34]. When the photon energy is equal to or exceeded the band gap energy $\mathrm{Eg}$, the electron-hole pairs are created in the semiconductor, dissociating into free photoelectrons in the conduction band and photoholes in the valence band, respectively.

Simultaneously, the photo-oxidation and reduction reactions occur in the presence of air, oxygen and pollutant molecules. During the reactions, the hydroxyl radical $(\mathrm{OH})$, coming from the oxidation of adsorbed water or $\mathrm{OH}^{-}$, is highly reactive. In addition, the reducing power of the electrons can induce the reduction of molecular oxygen $\left(\mathrm{O}_{2}\right)$ to superoxide $\mathrm{O}_{2}^{-}$. The highly reactive species $\mathrm{OH}$ and $\mathrm{O}_{2}^{-}$show strong ability to degrade micro-organisms [35,36] as well as organic [36,37] and inorganic pollutants $[37,38]$.

$\mathrm{TiO}_{2}$ photocatalysis is capable of destructing many organic contaminants completely, the activation can be written as follows [39]:

$$
\mathrm{TiO}_{2}+\mathrm{h} v \rightarrow \mathrm{h}^{+}+\mathrm{e}^{-}+\mathrm{TiO}_{2}
$$

In this reaction, the photonic excitation of the catalyst appears as the initial step of the whole catalytic system, the produced $\mathrm{h}^{+}$and $\mathrm{e}^{-}$are powerful oxidizing and reducing agents, respectively. The oxidation reaction:

$$
\mathrm{OH}^{-}+\mathrm{h}^{+} \rightarrow \mathrm{OH}
$$

The reduction reaction:

$$
\begin{gathered}
\mathrm{Ti}^{4+}+\mathrm{e}^{-} \rightarrow \mathrm{Ti}^{3+} \\
\mathrm{Ti}^{3+}+\mathrm{O}_{2} \rightarrow \mathrm{Ti}^{4+}+\mathrm{O}_{2}^{-}
\end{gathered}
$$

$\mathrm{OH}^{+}$pollutant $\rightarrow$ oxidised pollutant $\left(\mathrm{CO}_{2}, \mathrm{H}_{2} \mathrm{O}\right.$, etc. $)$

For a complete $\mathrm{PCO}$ reaction, the final products of reactions are harmless $\mathrm{CO}_{2}$ and $\mathrm{H}_{2} \mathrm{O}$, as well as few amounts of sulfates and chlorides. However, intermediates have been detected in some PCO processes. For example, Benoit-Marquie et al. [40] found that both butanal and 1-butanoic acid were the intermediates of 1-butanol. Nimolos et al. [41] used ethanol as the reactant and found the following intermediates: acetaldehyde, acetic acid, formaldehyde and formic acid.

$$
\mathrm{h}^{+}+\mathrm{e}^{-} \rightarrow \text { thermal heat or luminescence }
$$

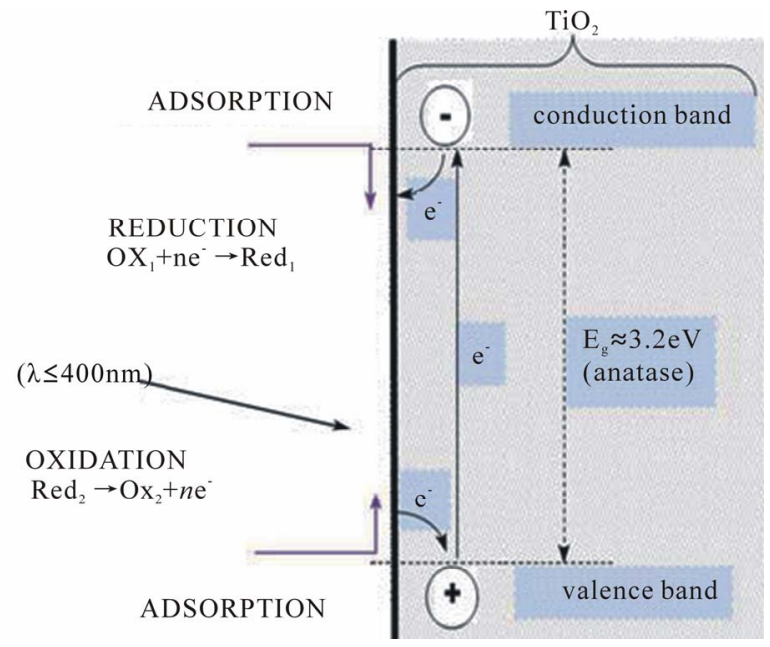

Figure 1. The schematic of $\mathrm{TiO}_{2} \mathrm{UV}$ photo-excitation process $(\mathrm{R}=$ reduction; $\mathrm{O}=$ oxidation $)$ [33].

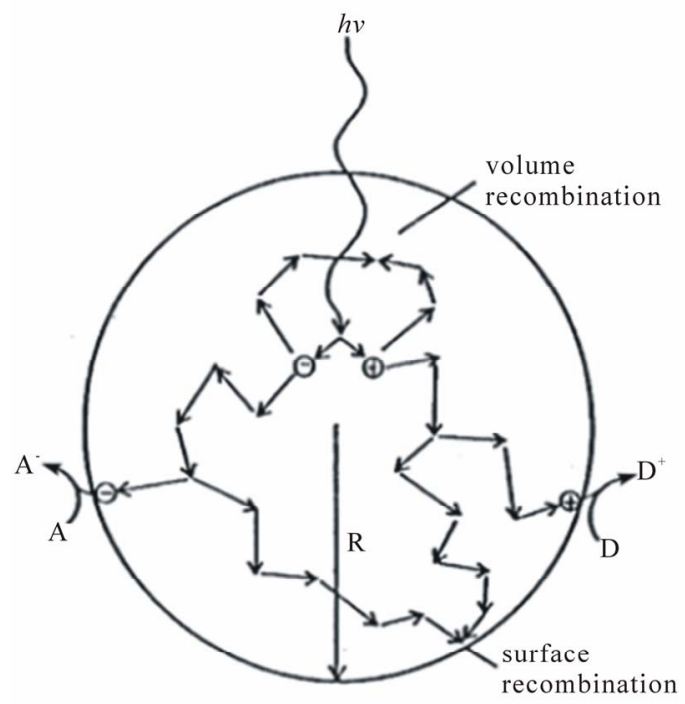

Figure 2. Fate of electrons and holes within a spherical particle of titania in the presence of acceptors (A) and (D) molecules [42].

Except the above reactions, there is also the electron-hole recombination (Figure 2). The PCO photoefficiency can be reduced by the electron-hole recombination, which corresponds to decreased electron and hole density as well as separation and the presence of oxygen can prevent the recombination of hole-electron pairs.

In short, the overall photocatalytic reactions can be decomposed into several steps, such as mass transfer of reactants from a fluidum (gas or liquid) to the photocatalyst surface, production of electron-hole, separation of the photogenerated electrons and holes, redox reactions between the trapped electrons and holes and adsorbed reactants, as well as desorption products and reconstruction of the surface. 
Reaction mechanism of PCO reaction is a key issue for practical application. It is important to reveal the reactions of the PCO. However, few investigations have been conducted in this area. During the reactions, various intermediates will be produced and some of these intermediates will poison the active sites resulting in deactivation of catalysts. In addition, the produced intermediates can be more toxic to human health and should be removed or further oxidised to $\mathrm{CO}_{2}$. Future research should be also focused on the detection of intermediates and their further re-adsorption and oxidation.

\section{PHOTOCATALYSTS}

The solids that can promote reactions in the presence of light but are not consumed in the overall reaction are referred as photocatalysts [28]. A photocatalyst for the reaction process needs to meet the following criteria: 1) photo-active; 2) utilizing near-UV light; 3) biologically and chemically inert; 4) photo-stable; 5) inexpensive and 6) non-toxic. Development of active photocatalyst systems is crucial for the PCO reaction.

For a semiconductor to be photochemically active as a sensitizer for the aforementioned reaction, the redox potential of the photogenerated valence band hole should be sufficiently positive to generate $\mathrm{OH}$ radicals that can subsequently oxidize the organic pollutants. The redox potential of the photogenerated conductance band electron must be sufficiently negative to be able to reduce the adsorbed $\mathrm{O}_{2}$ to a superoxide $\mathrm{O}_{2}^{-}$.

To date, semiconductors such as $\mathrm{TiO}_{2}, \mathrm{ZnO}, \mathrm{ZnS}, \mathrm{CdS}$, $\mathrm{Fe}_{2} \mathrm{O}_{3}, \mathrm{SnO}_{2}$ have been found to have sufficient band-gap energies for promoting photocatalytic activities. Among plentiful of semiconductors, $\mathrm{TiO}_{2}$ nanostructures are regarded as the most promising photocatalysts for the degradation of pollutants in water and air. The band-gap of several semiconductors is presented in Figure 3.

Of all the various semiconductors photocatalysts tested, $\mathrm{TiO}_{2}$ is the most suitable semiconductors for

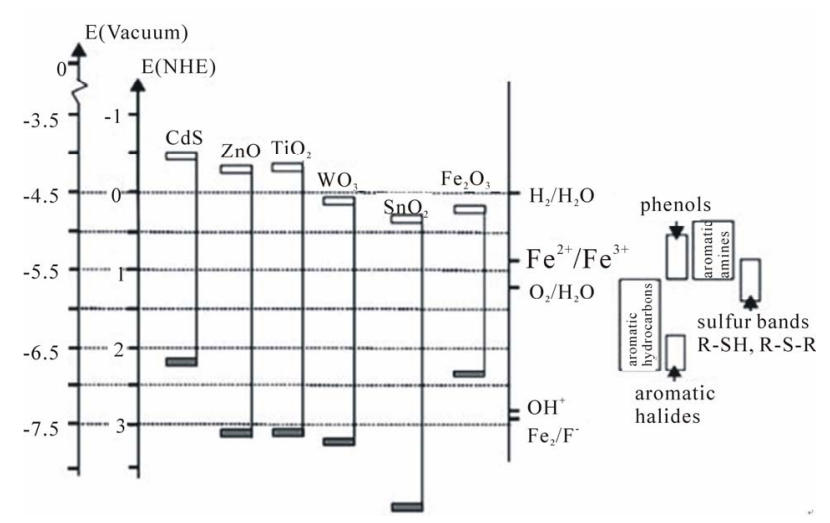

Figure 3. Band positions (top of valence band and bottom of conduction band) of several semiconductors together with some selected redox potentials [13]. photocatalytic reactions due to its superior characteristics [43]. Moreover, $\mathrm{TiO}_{2}$ promotes ambient temperature oxidation of most indoor air pollutants and does not need any chemical additives.

In the following, UV-light irradiated catalysts and visible light irratiated catalysts are introduced respectively.

\subsection{UV-Light Irradiated Catalysts}

At the early stage of photocatalyst development, a commercially available Degussa $\mathrm{P} 25 \mathrm{TiO}_{2}$ has been used as a standard photocatalyst for oxidation of gaseous or aqueous pollutants under UV or near-UV light due to its high photoactivity, excellent stability and low cost. Most of the investigations for indoor air photocatalytic oxidation used this catalyst.

Obee and Brown [44] pioneered reported an investigation of photocatalytic oxidation of VOCs using $\mathrm{TiO}_{2}$ for indoor air. In the investigation, an important finding was that competitive adsorption between water and trace contaminants of VOCs has a significant effect on the oxidation rate. Subsequently, the photooxidation of toluene and formaldehyde titania on glass-plate reactor and compared the results of two reactor designs were reported by the same group [45]. A design model was also developed the proposed two reactors.

The particle size affects the catalyst activity. Cao et al. [46] developed nanoscaled $\mathrm{TiO}_{2}$ photocatalysts. The photocatalyst nanostructures, composed mainly of mesopores with pore size in the range of $35-44 \mathrm{~nm}$ showed higher photoactivity than $\mathrm{P} 25 \mathrm{TiO}_{2}$. Then they used the nanoscale $\mathrm{TiO}_{2}$ catalysts for the photocatalytic oxidation of toluene [47]. The nanoscale $\mathrm{TiO}_{2}$ samples were found to be highly active for the photodegradation of toluene. However, performing the reaction at room temperature resulted in rapid deactivation of $\mathrm{TiO}_{2}$ catalysts due to the chemisorption of intermediates, such as benzaldehyde and benzoic acid.

A $\mathrm{TiO}_{2}$-coated fibre glass mesh composed of anatase $\mathrm{TiO}_{2}$ and $\mathrm{SiO}_{2}$ was first employed for photocatalytic oxidation of benzene, toluene and xylenes in indoor air [48]. The average concentrations of benzene, toluene and xylenes were indeed reduced by a factor of $2-3$ in an ordinary nonairtight room (Figure 4). $\mathrm{O}_{3}$ addition in $\mathrm{O}_{2}$ markedly increases the mineralisation percentage of $n$ octane, under otherwise identical conditions, in the laboratory photoreactor without photoexcitation of $\mathrm{O}_{3}$.

Jo et al. [6] evaluated the application of P25 $\mathrm{TiO}_{2}$ photocatalyst for the removal of five target VOCs, benzene, ethyl benzene, and o-, m-, p-xylenes in-vehicle air. Under the experimental conditions, the PCO destruction efficiencies were close to $100 \%$. They further extended the investigation to chlorinated VOCs, trichloroethylene (TCE) and perchloroethylene (PCE) under non-occupa- 


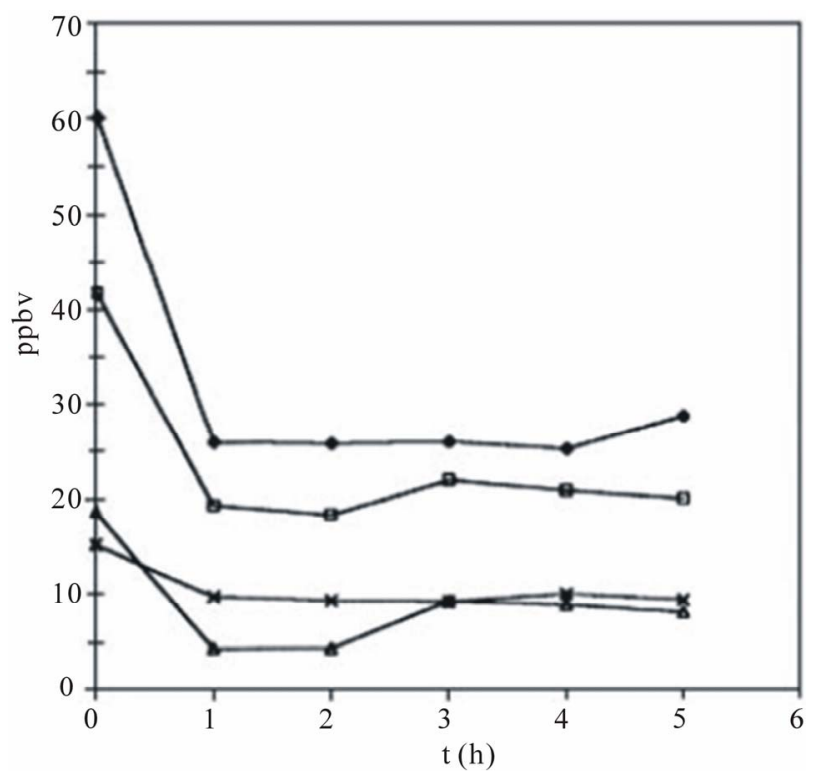

Figure 4. Decreases in the concentrations of benzene (crosses), toluene (diamonds), o-xylene (triangles) and both $\mathrm{m}$ - and p-xylene (squares) in a non-air tight roomcaused by the prototype air purifier; $t=0$ refers to the concentrations before the purifier UV lamps were switched on [48].

tional indoor air quality. The PCO destruction of VOCs was up to nearly $100 \%$, and the $\mathrm{CO}$ generated during PCO was a negligible addition to indoor CO levels [49].

Shiraishi et al. [50] developed a high-performance photocatalytic reactor with a parallel array of nine light sources for photocatalytic decomposition of gaseous formaldehyde at a very low concentration using amorphous $\mathrm{TiO}_{2}$. The experimental result indicateed that this photocatalytic reactor could rapidly decompose formaldehyde completely.

The application of employing artificial UV-light has the potential of being made more economical if the artificial UV is replaced by solar UV.

\subsection{Visible-Light Irradiated Catalysts}

The commonly used $\mathrm{TiO}_{2}$ is an effective catalyst in photocatalytic oxidation. However, this type of catalysts only exhibit high catalytic activity in UV-light span, the usage indoors or inside vehicles is still a challenge. Few $\mathrm{TiO}_{2}$ catalysts exhibit high activity for VOCs degradation under visible-light irradiation which hinder their practical application. In order to extend the applicable wavelength range and widen the practical applications, recent efforts focus on the doping of $\mathrm{TiO}_{2}$ by metal ions like iron and tungsten and non-metal species like carbon, nitrogen and sulphur in order to reduce the band gap energy [51].

Anpo and Takeuchi [52] reported that the metal ion implanted catalysts were able to absorb the light in wavelengh of $400-600 \mathrm{~nm}$ and thus worked well in the visible-light region. And the order of effectiveness in the red shift was found to be $\mathrm{V}>\mathrm{Cr}>\mathrm{Mn}>\mathrm{Fe}>\mathrm{Ni}$. It was further observed that both the depth the metal ions inserted and the number of metal ions implanted influenced the photocatalytic activity. The results showed that there were optimal conditions in the depth and the number of metal ions implanted to achieve high photocatalytic activity under visible-light irradiation.

Yamashita et al. [53] have reported on the usage of metal ions implanted $\mathrm{TiO}_{2}$ catalysts $\left(\mathrm{V}^{+}, \mathrm{Mn}^{+}\right.$and $\left.\mathrm{Fe}^{+}\right)$ for the decomposition of propanol in the visible-light medium. The implanted metal ions were located at the lattice positions of $\mathrm{Ti}^{4+}$ in $\mathrm{TiO}_{2}$ after the calcination, which was improtant to modify $\mathrm{TiO}_{2}$ to be able to adsorb visible-light and operate as robust visible-light photocatalysts.

$\mathrm{Wu}$ and Chen [54] have also reported that vanadium doping provided a promising strategy to improve the photocatalytic activity of $\mathrm{TiO}_{2}$ under visible light. The increase in vanadium doping increased the absorption of the light towards the visible region because vanadium was present in the $\mathrm{V}^{4+}$ state either by substituting $\mathrm{Ti}^{4+}$ in its site or embedded in the vacancy of the $\mathrm{TiO}_{2}$ structure.

Fuerte et al. [55] reported the preparation and application of titanium-tungsten mixed oxides in the photocatalytic degradation of toluene using sunlight-type excitation. The photocatalytic activity of Ti-W mixed oxides increased with $\mathrm{W}$ content and is much better than $\mathrm{TiO}_{2}$ itself and $\mathrm{TiO}_{2} \mathrm{P} 25$.

However, Chapuis et al. [56] found that doping of $\mathrm{TiO}_{2}$ by metal oxides such as $\mathrm{Ag}_{2} \mathrm{O}, \mathrm{CuO}, \mathrm{NiO}, \mathrm{CoO}$, and $\mathrm{Cr}_{2} \mathrm{O}_{3}$ gave much lower catalytic conversion. And nanosized doping $\mathrm{TiO}_{2}$ photocatalysts were more effective in the degradation of toluene than $\mathrm{TiO}_{2}$ itself and $\mathrm{P} 25 \mathrm{TiO}_{2}$

Another new approach of synthesizing visible-light activated $\mathrm{TiO}_{2}$ photocatalysts is by doping with anions, such as $\mathrm{N}^{3-}, \mathrm{C}^{4-}, \mathrm{S}^{4-}$ or halides $\left(\mathrm{F}^{-}, \mathrm{Cl}^{-}, \mathrm{Br}^{-}, \mathrm{I}^{-}\right)$[57]. It was suggested that these species substitute the oxygen lattice on $\mathrm{TiO}_{2}$ and lead to a band gap narrowing, resulting in high visible absorption.

Doping with non-metallic species also causes the photosensitization of $\mathrm{TiO}_{2}$ semiconductor in the visible light like $\mathrm{C}, \mathrm{N}$ and $\mathrm{S}$.

For carbon modified $\mathrm{TiO}_{2}$ photocatalysts, Lettmann et al. [58] reported the synthesis of photocatalysts based on $\mathrm{TiO}_{2}$ by modified sol-gel process using various alkoxide precursors. It was seen that the employment of alcohols pyrolysis in the sol-gel process leaded to carbonaceous species embedded within the $\mathrm{TiO}_{2}$ matrix which were responsible for the observed visible light sensitization of $\mathrm{TiO}_{2}$ semiconductor.

Many investigations have described the enhanced photocatalytic properties of $\mathrm{TiO}_{2}$ by $\mathrm{N}$ doping. Asahi et 
al. first reported the visible-light photocatalysis in $\mathrm{N}-$ doped $\mathrm{TiO}_{2}$ [59]. They tested various $\mathrm{TiO}_{2}-\mathrm{xNx}$ catalysts for VOCs decomposition. These catalysts were found to photodegrade gaseous acetaldehyde [59], acetone [60] and 2-propanol [61] upon irradiation of visible-light. Recently, Irokawa et al. [62] have reported the photooxidation of aromatics over $\mathrm{N}$-doped $\mathrm{TiO}_{2}\left(\mathrm{TiO}_{2}\right.$-xNx) under visible-light irradiation. They used toluene as test compound. Results indicated that toluene, weakly adsorbed on the catalyst surface, was initially photooxidised to benzaldehyde which firmy adsorbed onto the $\mathrm{TiO}_{2}-\mathrm{xNx}$ surface, leading to the formation of ringopening products such as carboxylic acids and aldehydes. Major intermediates adsorbed at the catalyst surface were gradually photodegraded to $\mathrm{CO}_{2}$ and $\mathrm{H}_{2} \mathrm{O}$ under visiblelight irradiation.

Mesoporous nanocrystalline $\mathrm{TiO}_{2}-\mathrm{xNx}$ and $\mathrm{TiO}_{2}-\mathrm{xNx} /$ $\mathrm{ZrO}_{2}$ visible-light photocatalysts have been prepared by a sol-gel method. The photocatalytic activity of the samples was evaluated by the decomposition of ethylene in air under visible-light (lambda $\mathrm{N} 450 \mathrm{~nm}$ ) illumination. The introduction of $\mathrm{ZrO}_{2}$ into $\mathrm{TiO}_{2}-\mathrm{xNx}$ considerably inhibited the undesirable crystal growth during the calcinations and improved the efficiency of degradation of ethylene [63].

A series of nanosized $\mathrm{N}$-containing $\mathrm{TiO}_{2}$-based materials were also tested in the photocatalytic degradation of methylcyclohexene, a representative example of volatile organic compounds (VOCs) present in urban atmospheres. It was found that the samples contained substitutional and interstitial $\mathrm{N}$-containing impurities and a significant number of oxygen vacancies. Photocatalytic activity was correlated with an optimum of oxygen vacancies, above and below which a decrease of the steady state reaction rate was observed. The physico-chemical bases of this behaviour were discussed on the light of the above-mentioned experimental results [64].

Reports on band gap narrowing of $\mathrm{TiO}_{2}$ by sulfur doping are also available in the literature [65]. Degradation of methylene blue using S-doped $\mathrm{TiO}_{2}$ photocatalyst under visible light irradiation has been reported [66,67]; However, the degradation of catalytic activity, coming from catalytic poison caused by oxidation of $\mathrm{SO}_{2}$ to $\mathrm{SO}_{4}^{2-}$, has also been reportedly noticed in the decomposition of 2-proponal [68].

Recently, a novel nanocomposites of $\mathrm{Ag}-\mathrm{AgBr}-\mathrm{TiO}_{2}$ were prepared by a deposition-precipitation method [69]. The results showed that the nanocomposites exhibited much higher photocatalytic activity and stability under both UV light and visible-light irradiation as compared with that of $\mathrm{P} 25 \mathrm{TiO}_{2}$ toward aromatic benzene and non-aromatic acetone due to the synergetic effects between $\mathrm{Ag}-\mathrm{AgBr}$ and $\mathrm{TiO}_{2}$.

Many efforts have been made on the application of
PCO degradation VOCs under visible light, the results would be of great significance in developing visible-light or sunlight responsive photocatalytic materials.

\section{KINETIC PARAMETERS}

The reaction rate is an important parameter to evaluate the effciency of PCO. Lots of experimental results showed that the overall photocatalytic degradation rate was governed by physicochemical as well as producted related parameters, such as the effects of humidity, pollutant concentration, temperature, the UV-light intensity, the weight of catalysts, etc $[18,20,26,70]$.

In the following, a short and descriptive explanation of some key influencing parameters is given.

\subsection{Process Related Parameters}

\subsubsection{Adsorption Rate}

Adsorption of pollutants on the titania surface is one of the most important parameter affecting the catalyst performance. The adsorption trends of these pollutants may determine their conversion rate [71]. As shown in Figure 5 , ethylene undergoes a lower adsorption phenomenon compared to the other hydrocarbons tested, whereas propylene has slightly higher adsorption than ethylene on the optimized $\mathrm{TiO}_{2}$ nano particles surface. Compared to both ethylene and propylene, toluene has very high adsorption which attributes a multilayer adsorption. The adsorption of pollutants is proportional to the enrichment of pollutants on the surface of catalyst and the faster the degradation rate.

\subsubsection{Light Spectrum}

As to the PCO reaction, the photonic excitation of the catalyst appears as the initial step of the activation of the whole catalytic system. When photons of a certain wavelength hit its surface, electrons are promoted from the valence band and transferred to the conductance band. This leaves positive holes in the valence band, which then reacts with the hydroxylated surface to produce $\mathrm{OH}$ radicals, the true oxidizing agents. Thus the spectrum of the light source has the dramatic effect on the photodegradation of the reactants.

The variation of the reaction rate as a function of the wavelength follows the absorption spectrum of the catalyst (Figure 6(b)), with a threshold corresponding to its band gap energy.

\subsubsection{Initial Concentration of VOCs}

Another important factor that should be discussed is the concentration of the VOCs. Generally, the influence of the pollutant concentration plays an important role during the PCO reaction. Different contaminant concentrations lead to different reaction rates. The influence of the pollutant concentration in the lower range results in a 


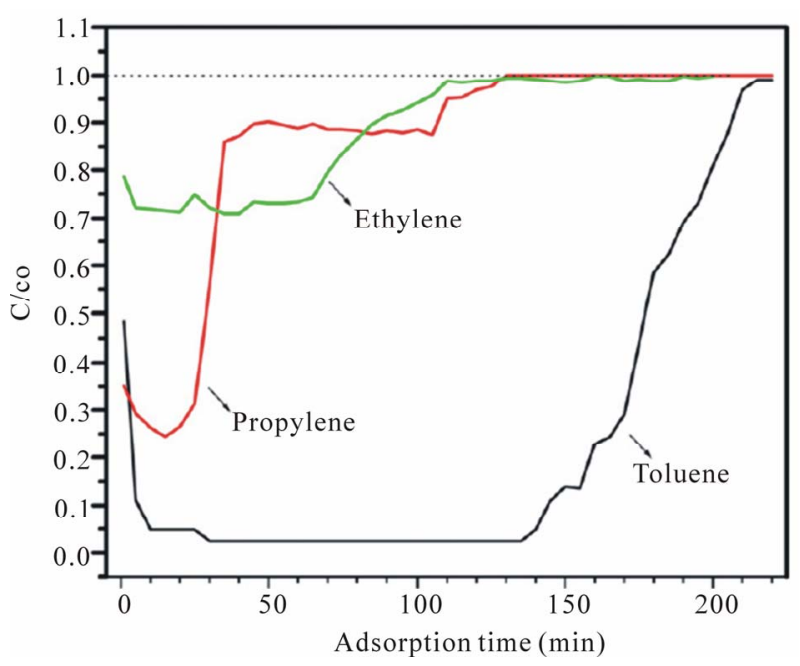

Figure 5. Adsorption of ethylene, propylene and toluene at optimized TNP photocatalyst.

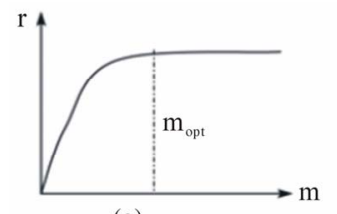

(a)

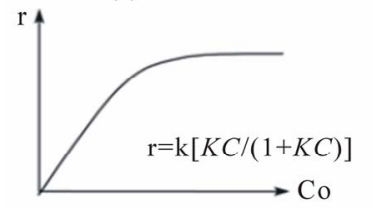

(c)

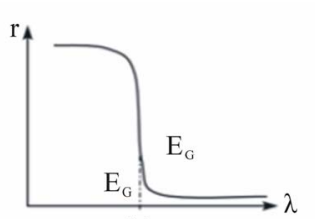

(b)

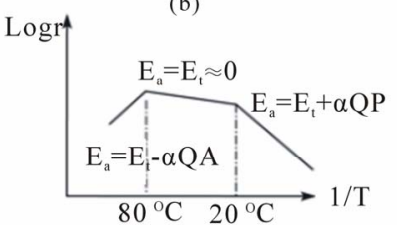

(d)

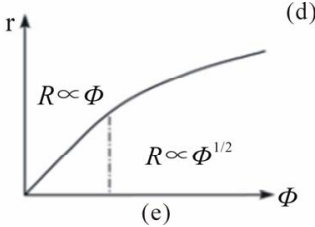

Figure. 6 Influence of different physical parameters governing the reaction rate [72]. (a) Mass of catalysts; (b) Wavelength; (c) Initial concentration of reactants; (d) Temperature; (e) Radiant flux.

remarkable higher changes of the degradation rate than that of in the range of higher concentrations.

Obee and Hay [73] found that the reaction rate of ethylene was enhanced by increasing concentrations of pollutants. Noguchi et al. [74] and Cao [75] employed formaldehyde and 1-butene as target reactants and found that the reaction rate was enhanced by increasing the initial contaminant concentration. In Cao's research, the reaction rate did not change largely when concentration of 1-butene was higher than 7 ppmv. In Noguchi et al.'s research, the increasing rate of the reaction rate slowed down when the initial concentration of formaldehyde was higher than 600 ppmv. They further gave the following results with regard to formaldehyde and acetal-

dehyde: in the low contaminant concentration region (less than $1200 \mathrm{ppmv}$ ), the degradation rate of formaldehyde was higher than that of acetaldehyde because the adsorption strength of formaldehyde on the catalyst surface was higher.

The rate equations can be used to explain the related results. The rate equations follow a Langmuir-Hinshelwood mechanism confirming the catalytic characteristic of the system with the rate $r$ varying proportionally with the coverage $\theta$ as below:

$$
r=k \theta=k(\mathrm{KC} /(1+\mathrm{KC}))
$$

For diluted solutions $\left(\mathrm{C}<10^{-3} \mathrm{M}\right), \mathrm{KC}$ becomes $\ll 1$ and the reaction is of the apparent first order, whereas for concentrations $>5 \times 10^{-3} \mathrm{M},(\mathrm{KC} \ll 1)$, the reaction rate is maximum and of the apparent order (Figure 6(c)). In the gas phase, similar Langmuir-Hinshelwood expressions have been found including partial pressures $\mathrm{P}$ instead of C.

\subsubsection{Reaction Temperature}

Because of the photonic activation, the photocatalytic systems do not require heating and usually operate at room temperature. The true activation energy Et is nil, whereas the apparent activation energy Ea is often very small (a few $\mathrm{kJ} / \mathrm{mol}$ ) in the medium temperature range $\left(20^{\circ} \mathrm{C} \leq \theta \leq 80^{\circ} \mathrm{C}\right)$. However, at very low temperatures $\left(-40^{\circ} \mathrm{C} \leq \theta \leq 0^{\circ} \mathrm{C}\right)$, the activity decreases and the activation energy Ea becomes positive (Figure 6(d)).

By contrast, for various types of photocatalytic reactions at "high" temperatures $\left(\theta \geq 70^{\circ} \mathrm{C}-80^{\circ} \mathrm{C}\right)$, the activity decreases and the apparent activation energy becomes negative (Figure 6(c)). This behavior can be easily explained within the frame of the Langmuir-Hinshelwood mechanism described above. The decrease in temperature favors adsorption (which is a spontaneous exothermic phenomenon) with in particular that of the final product, which becomes the inhibitor of the reaction. By contrast, when $\theta$ increases above $80^{\circ} \mathrm{C}$ and tends to the boiling point of water, the exothermic adsorption of reactant $\mathrm{A}$ becomes disfavored and tends to become the rate limiting step of the whole reaction.

As a consequence, the optimum temperature is generally between $20^{\circ} \mathrm{C}$ and $80^{\circ} \mathrm{C}$. This explains why solar devices which use light concentrators instead of light collectors require coolers [76].

Hussain et al. [71] also investigated the affects of the operating temperature. The results showed that a small increase in temperature to $35^{\circ} \mathrm{C}$, suggesting an increase in the ethylene conversion. Conversely, when a higher temperature of $80^{\circ} \mathrm{C}$ was reached, a decrease was observed. A similar trend was observed for propylene and toluene, and the highest conversion was shown at $40^{\circ} \mathrm{C}$. This was due to the best compromise between the in- 
crease in reaction kinetics and the decrease in adsorption entailed by the temperature rise.

\subsubsection{Radiant Flux}

Not only the wavelength is one of the influencing factors of the system's efficiency but also the intensity of the radiation or so-called irradiance $\mathrm{E}$ has an effect on the degradation rate [77].

The activity of the photocatalyst depends strongly on the light-irradiation $\mathrm{E}$ or the photon flux on the surface of the catalyst. It has been shown that for all types of photocatalytic reactions, the reaction rate $r$ is proportional to the radiant flux $\Phi$ (Figure 3(e)). This confirms the photo-induced nature of the activation of the catalytic process, with the participation of photo-induced electron-hole pairs to the reaction mechanism. However, the linear behavior for values could not be verified under a low irradiance [51], during which, the reaction rate $\mathrm{r}$ becomes proportional to $\Phi 1 / 2$, indicating strong electron-hole recombination. These two regimes have been independently demonstrated by Egerton et al. [78] and the author $[79,80]$.

\subsubsection{Relative Humility}

The influence of the relative humidity depends to a large extent on the characteristics of contaminants [81]. It has been observed that the surface $\mathrm{OH}$ groups and/or physisorbed $\mathrm{H}_{2} \mathrm{O}$, as well as the anion radicals, can play a significant role as key active species in the $\mathrm{PCO}$ reaction of various VOCs [71]. In the absence of water vapor, the photocatalytic degradation of some chemical compounds (e.g., toluene, formaldehyde) is seriously retarded and the total mineralization to $\mathrm{CO}_{2}$ does not occur. However, excessive water vapor on the catalyst surface will lead to the decrease of reaction rate because water molecules can occupy the active sites of the reactants on the surface and the hydrophilic effect at the surface prevails over the oxidizing effect [12]. According to Beeldens [82], the hydrophilic effect at the surface prevails over the oxidizing effect when high values of relative humidity are applied.

$\mathrm{TiO}_{2}$ surface carries weakly or strongly bound molecular water, as well as hydroxyl groups created by the dissociative chemisorption of water.

Obee and Brown [3] investigated the effect of humility on photooxidation rate of formaldehyde, toluene, and 1 , 3-butadiene on titania. The data showed that competitive adsorption between water and trace contaminants had a significant effect on the oxidation rate.

However, Jo et al. [6,49] found that the humidity had little effect on photocatalytic oxidation of benzene, ethyl benzene, and o-, m-, p-xylenes, trichloroethylene, and perchloroethylene. The PCO destruction efficiencies were close to $100 \%$ for four different $\mathrm{RH}$ ranges from 18 to $78 \%$. Ao and Lee [83] compared the effect of humidity on photocatalytic oxidation of BTEX on $\mathrm{TiO}_{2}$ and $\mathrm{TiO}_{2} /$ $\mathrm{AC}$ systems and the results indicated that $\mathrm{TiO}_{2} / \mathrm{AC}$ exhibited higher resistance to humidity effect. This negative effect of water vapour on TOL removal was in agreement with results obtained by other authors investigating photocatalytic TOL degradation by $\mathrm{TiO}_{2} / \mathrm{UV}$ [47].

The practical evaluation by installation of the $\mathrm{TiO}_{2} / \mathrm{AC}$ filter in an air cleaner was also conducted. The use of $\mathrm{TiO}_{2} / \mathrm{AC}$ not only increased the target pollutant removal efficiency but also reduced the amount of intermediate exiting the system. The study showed that the enhancement effect of the $\mathrm{TiO}_{2} / \mathrm{AC}$ shown in the laboratory scale using the photoreactor was also achieved by installing it into an air cleaner available in the commercial market [84].

Except the factors, the volatile organic compound structure is also an important feature. O'Malley and Hodnett [85] found that a primary factor in determining the reactivity of volatile organic compounds in oxidation reaction was the strength of the weakest $\mathrm{C}-\mathrm{H}$ bond in the structure, which implicted that destruction of volatile organic compounds over oxidation catalysts proceeded by initial rupture of the weakest $\mathrm{C}-\mathrm{H}$ bond in the compound, followed by further steps that may involve free radical chemistry. The research showed that the reactivity of VOCs with different functional groups for total oxidation varied as alcohols $>$ aromatics $>$ ketones $>$ carboxylic acids $>$ alkanes.

\subsection{Product Related Parameters}

Besides varying experimental parameters, the influence of product related parameters like crystalline structure of $\mathrm{TiO}_{2}$, the mass of the $\mathrm{TiO}_{2}$ and surface of the catalyst is also investigated $[86,87]$.

\subsubsection{Mass of Catalysts}

Herrmann [77] investigated the relationship between the initial rates of photocatalytic reaction and the mass of catalysts. The results indicated that the initial rates of reactions were found to be directly proportional to the mass $m$ of catalysts (Figure 6(a)). This indicated a true catalytic regime. Due to the increased weight, photocatalyst has higher surface area and more porosity, which offers larger specific surface areas and caused the higher adsorption and consequently the higher conversion. However, above a certain value of $\mathrm{m}$, the reaction rate levels off and becomes independent of $\mathrm{m}$. This limit depends on the mass transfer and light penetration limitations, which entailed that the increase in the available catalyst mass did not actually lead to an increase in terms of increased pollutants conversion.

For higher amounts of catalysts, a screening effect of 
multilaters occurs, which masks part of the photosensitive surface and were not accessible to the reaction. For applications, this optimum mass of catalysts has to be chosen in order 1) to avoid an unuseful excess of catalysts and 2) to ensure total absorption of efficient photons.

\subsubsection{Crystalline Forms of $\mathrm{TiO}_{2}$}

In solid state, $\mathrm{TiO}_{2}$ can appear in three different crystalline modifications namely: rutile (tetragonal), anatase (tetragonal) and the seldom brookite (orthorhombic).

Among these crystalline forms, rutile is thermodynamically the most stable, whereas anatase and brookite are metastable and transform to rutile on heating. In spite of this similarity between anatase and brookite, the last one occurs rarely compared to the anatase form of $\mathrm{TiO}_{2}$ and exhibits no significant photocatalytic activity under daylight irradiation. Rutile and anatase have more industrial applications.

Most of the studies have shown that the photocatalytic activity of titanium dioxide is influenced to a great extent by the crystalline form, although controversial results have also been reported in the literature. Some authors have stated that anatase works better than rutile [24], others have found the best photocatalytic activity for rutile [88], and some others have detected synergistic effects in the photocatalytic activity for anatase-rutile mixed phases [89]. It has recently been demonstrated that photo-activity towards organic degradation depends on the phase composition and on the oxidizing agent; for example, when the performance of different crystalline forms was compared, it was discovered that rutile shows the highest photocatalytic activity with $\mathrm{H}_{2} \mathrm{O}_{2}$, whereas anatase shows the highest with $\mathrm{O}_{2}$ [90].

It is generally accepted that anatase demonstrates a higher activity than rutile, for most photocatalytic reaction systems, and this enhancement in photoactivity has been ascribed to the fact that the Fermi level of anatase is higher than that of rutile [91]. The precursors and the preparation method both affect the physicochemical properties of the specimen. In recent years, Degussa P25 $\mathrm{TiO}_{2}$ has set the standard for photoreactivity in environmental VOC applications. Degussa P25 is a non-porous 70\%:30\% (anatase to rutile) material. Despite the presence of the rutile phase, this material has proved to be even more reactive than pure anatase [26]. Therefore, a mixed anatase-rutile phase seems to be preferable to enable some synergistic effects for photocatalytic reactions since the conduction band electron of the anatase partly jumps to the less positive rutile part, thus reducing the recombination rate of the electrons and positive holes in the anatase part.

\subsubsection{Effects Surface Areas}

The surface area is another important factor that affect
VOCs degradation in catalytic oxidation reactions [28]. The high surface area results in more adsorption sites for pollutants to be oxidized.

Zou et al. [92] reported that the catalyst with higher surface area $\left(421.1 \mathrm{~m}^{2} / \mathrm{g}\right)$ achieved $100 \%$ conversion efficiency for a substantial period of about $4 \mathrm{~h}$, whereas the catalyst with a low surface area only had a very brief period of $100 \%$ conversion efficiency. This can be explained by the higher surface area of the porous catalyst material, increasing the adsorption capacity. These experimental results demonstrated that it was possible to achieve desirable degradation efficiency using the innovative $\mathrm{TiO}_{2}-\mathrm{SiO}_{2}$ photocatalyst. Within the regeneration limits, the adsorption enhanced the photocatalysis for better overall degradation. The surface structure was, in this respect, found to have a major influence. Surfaces with high roughness are providing more active surface area than smooth surfaces.

Moreover, the ability of $\mathrm{TiO}_{2}$ particles to degrade organic compounds also depended on the size of the particles, since the smaller the particle size, the larger specific surface areas and the better catalyst activity.

It has also been found that photoformed $\mathrm{OH}$ species, as well as $\mathrm{O}_{2}^{-}$and $\mathrm{O}_{3}^{-}$anion radicals, play a significant role as a key active species in the complete photocatalytic oxidation of ethylene with oxygen into carbon dioxide and water [10].

Attempts should be made to obtain catalyse with a high surface area and a mixed crystalline phase with more anatase and small amounts of rutile. Instead, in the present work, an attempt has been made to optimize catalyst by optimizing the synthesis operating conditions.

\section{SUMMARY AND PERSPECTIVES}

Indoor air quality is currently a public intensive concern. VOCs are important indoor air pollutions. The most promising approach of improving the indoor quality is the PCO. Great efforts have been made on the PCO. However, the technique is still in the initial stage for VOCs removal from indoor air.

$\mathrm{TiO}_{2}$ is widely used as photocatalyst. However, it merely exhibits high catalytic activity under UV-light, how to $\mathrm{make}^{\mathrm{TiO}}{ }_{2}$ photosensitized in the visible by doping or other methods or to develop novel photocatalyst, different from $\mathrm{TiO}_{2}$ and directly active in the visible is highly demanded. More research should be directed in the development of effective visible-light or solar light irradiated photocatalysts and also in testing the photodegradation of indoor pollutions. Furthermore, nanoscaled photocatalysts exhibited higher activity on the PCO, great efforts should be made to fabricate nano photocatalysts at a large scale by adjusting conditions and the synthesis conditions. The development of nano technologies make the PCO promising for future research and 
further applications.

For a complete $\mathrm{PCO}$ reaction, the final products of reactions are harmless $\mathrm{CO}_{2}$ and $\mathrm{H}_{2} \mathrm{O}$. However, intermediates have been detected in some PCO processes. Ring the reaction, various intermediates will be produced and some of these intermediates will poison the active sites resulting in deactivation of catalysts. In addition, the produced intermediates can be more toxic to human health and should be removed or further oxidised to $\mathrm{CO}_{2}$. Thus, how to avoid the intermediates is also a hard task. Future research should be focused on the detection of intermediates and their further readsorption and oxidation. Modelling of catalytic reactor performance should also be developed for a pilot scale practice.

A variety of products containing $\mathrm{TiO}_{2}$ are already available on the European market and their working mechanism under laboratory conditions is proven. However, there is still a lack of transforming the experimental results obtained under laboratory conditions to practical applications considering real world conditions. The potential applications strongly depend on the future development of photocatalytic engineering.

Novel $\mathrm{TiO}_{2}$ nanopaticles showed a superior catalytic performance of VOCs than that of $\mathrm{P} 25 \mathrm{TiO}_{2}$. Thus, the development of nano-scale $\mathrm{TiO}_{2}$ photocatalysts with anatase-rutile mixed phase, high specific surface area, good porosity is promising for future research and further applications.

A variety of novel photocatalysts, such as $\mathrm{Fe}_{2} \mathrm{O}_{3}$, $\mathrm{TiO}_{2}, \mathrm{Cu}_{2} \mathrm{O}, \mathrm{WO}_{3}, \mathrm{ZnS}$ and $\mathrm{CdS}$ can be prepared with the synergetic photocatalytic effect between $\mathrm{Ag}-\mathrm{AgBr}$ and semiconductors. This would advance the application of nanocomposites as photocatalyst for the degradation of harmful VOCs and widely optimize the photocatalytic performance.

Although development and application of PCO still need improvement, the potential for a wider use of this technology is huge and promising.

\section{ACKNOWLEDGEMENTS}

This work was supported by the National Nature Science Foundations of China (21071098), the China International Science and technology Cooperation Project (2011DFA50530), Shandong Provincial Natural Science Foundation (ZR2011BQ017), China, Seed Fund from Ocean University of China, and Fundamental Research Funds for the Central Universities (201313001).

\section{REFERENCES}

[1] Jacoby, W.A., Blake, D.M., Noble, R.D., et al. (1995) Kinetics of the oxidation of trichloroethylene in air via heterogeneous photocatalysis. Journal of Catalysis, 157, 87-96. doi:10.1006/jcat.1995.1270

[2] Peral, J. and Ollis, D.F. (1991) Heterogeneous photo- catalytic oxidation of gas-phase organics for air purification: Acetone, 1-butanol, butyraldehyde, formaldehyde, and mxylene oxidation. Journal of Catalysis, 136, 554565. doi:10.1016/0021-9517(92)90085-V

[3] Obee, T.N. and Brown, R.T. (1995) $\mathrm{TiO}_{2}$ photocatalysis for indoor air applications: Effects of humidity and trace contaminant levels on the oxidation rates of formaldehyde, toluene, and 1,3-butadiene. Environmental Science and Technology, 29, 1223-1231. doi:10.1021/es00005a013

[4] Alberici, R.M. and Jardim W.F. (1997) Photocatalytic destruction of VOCs in the gas-phase using titanium dioxide. Applied Catalysis B: Environmental, 14, 55-68.

[5] Tsoukleris, D.S., Maggos, T., Vassilakos, C., et al. (2007) Photocatalytic degradation of volatile organics on $\mathrm{TiO}_{2}$ embedded glass spherules. Catalyst Today, 129, 96-101. doi:10.1016/j.cattod.2007.06.047

[6] Jo, W.K., Park, J.H. and Chun H.D. (2002) Photocatalytic destruction of VOCs for in-vehicle air cleaning. Journal of Photochemistry and Photobiology A: Chemistry, 148, 109-119. doi:10.1016/S1010-6030(02)00080-1

[7] Derwent, R.G., Jenkin, M.E., Saunders, S.M., et al. (2003) Photochemical ozone formation in north west Europe and its control. Atmospheric Environment, 37, 1983-1991. doi:10.1016/S1352-2310(03)00031-1

[8] Yu, H., Zhang, K. and Rossi C. (2007) Theoretical study on photocatalytic oxidation of VOCs using nano- $\mathrm{TiO}_{2}$ photocatalyst. Journal of Photochemistry and Photobiology A: Chemistry, 188, 65-73.

doi:10.1016/j.jphotochem.2006.11.021

[9] Ray, M.B. (2000) Photodegradation of the volatile organic compounds in the gas phase: A review. Develpoment and Chemistry Engineering Mineral Process, 8, 405-439. doi:10.1002/apj.5500080502

[10] Kumar, S., Fedorov, A.G. and Gole, J.L. (2005) Photodegradation of ethylene using visible light responsive surfaces prepared from titania nanoparticle slurries. $A p$ plied Catalysis B: Environmental, 57, 93-107.

[11] Everaert, K. and Baeyens, J. (2004) Catalytic combustion of volatile organic compounds. Journal of Hazardous Materials, 109, 113-139. doi:10.1016/j.jhazmat.2004.03.019

[12] Zhao, J. and Yang, X.D. (2003) Photocatalytic oxidation for indoor air purification: A literature review. Building and Environment, 38, 645-654. doi:10.1016/S0360-1323(02)00212-3

[13] Carp, O., Huisman, C.L. and Reller, A. (2004) Photoinduced reactivity of titanium dioxide. Progress in Solid State Chemistry, 32, 33-177. doi:10.1016/j.progsolidstchem.2004.08.001

[14] Benoit-Marquié, F., Wilkenhoner, U., Simon, V., et al. (2000) VOC photodegradation at the gas-solid interface of a $\mathrm{TiO}_{2}$ photocatalyst. Part I. 1-butanol and 1-butylamine. Journal of Photochemistry and Photobiology A: Chemistry, 132, 225-232. doi:10.1016/S1010-6030(00)00196-9

[15] Biomorgi, J., Oliveros, E., Coppel, Y., et al. (2010) Effect of V-UV-radiation on VOCs-saturated zeolites. Journal of Photochemistry and Photobiology A: Chemistry, 214, 
194-202. doi:10.1016/j.jphotochem.2010.06.026

[16] Martra, G., Coluccia, S., Marchese, L., et al. (1999) The role of $\mathrm{H}_{2} \mathrm{O}$ in the photocatalytic oxidation of toluene in vapour phase on anatase $\mathrm{TiO}_{2}$ catalyst: A FTIR study. Catalyst Today, 53, 695-702. doi:10.1016/S0920-5861(99)00156-X

[17] Muggli, D.S. and Ding, L. (2001) Photocatalytic performance of sulfated $\mathrm{TiO}_{2}$ and Degussa P-25 TiO 2 during oxidation of organics. Applied Catalysis B: Environmental, 32, 181-194.

[18] Zhang, P.Y., Liang, F.Y., Yu, G., et al. (2003) A comparative study on decomposition of gaseous toluene by $\mathrm{O}_{3} / \mathrm{UV}, \mathrm{TiO}_{2} / \mathrm{UV}$ and $\mathrm{O}_{3} / \mathrm{TiO}_{2} / \mathrm{UV}$. Journal of Photochemistry and Photobiology A: Chemistry, 156, 189-194. doi:10.1016/S1010-6030(02)00432-X

[19] Ao, C.H. and Lee, S.C. (2004) Combination effect of activated carbon with $\mathrm{TiO}_{2}$ for the photodegradation of binary pollutants at typical indoor air level. Journal of Photochemistry and Photobiology A: Chemistry, 161, 131140. doi:10.1016/S1010-6030(03)00276-4

[20] Sleiman, M., Conchon, P., Ferronato, C., et al. (2009) Photocatalytic oxidation of toluene at indoor air levels (ppbv): Towards a better assessment of conversion, reaction intermediates and mineralization. Applied Catalysis B: Environmental, 86, 159-165.

[21] Blount, M.C. and Falconer, J.L. (2002) Steady-state surface species during toluene photocatalysis. Applied $\mathrm{Ca}$ talysis B: Environmental, 39, 39-50.

[22] Fresno, F., Hernandez-Alonso, M.D., Tudela, D., et al. (2008) Photocatalytic degradation of toluene over doped and coupled $(\mathrm{Ti}, \mathrm{M}) \mathrm{O}_{2}(\mathrm{M}=\mathrm{Sn}$ or $\mathrm{Zr})$ nanocrystalline oxides: Influence of the heteroatom distribution on deactivation. Applied Catalysis B: Environmental, 84, 598-606.

[23] Zou, L., Luo, Y., Hooper, M., et al. (2006) Removal of VOCs by photocatalysis process using adsorption enhanced $\mathrm{TiO}_{2}-\mathrm{SiO}_{2}$ catalyst. Chemical Engineering and Processing, 45, 959-964. doi:10.1016/j.cep.2006.01.014

[24] Zuo, G.M., Cheng, Z.X., Chen, H., et al. (2006) Study on photocatalytic degradation of several volatile organic compounds. Journal of Hazardous Materials, 128, 158163. doi:10.1016/j.jhazmat.2005.07.056

[25] Deveau, P.A., Arsac, F., Thivel, P.X., et al. (2007) Different methods in $\mathrm{TiO}_{2}$ photodegradation mechanism studies: Gaseous and $\mathrm{TiO}_{2}$-adsorbed phases. Journal of Hazardous Materials, 144, 692-697. doi:10.1016/j.jhazmat.2007.01.097

[26] Augugliaro, V., Coluccia, S., Loddo, V., et al. (1999) Photocatalytic oxidation of gaseous toluene on anatase $\mathrm{TiO}_{2}$ catalyst: Mechanistic aspects and FT-IR investigation. Applied Catalysis B: Environmental, 20, 15-27.

[27] Hussain, M., Ceccarelli, R., Marchisio, et al. (2010) Synthesis, characterization, and photocatalytic application of novel $\mathrm{TiO}_{2}$ nanoparticles. Chemical Engineering Journal, 157, 45-51. doi:10.1016/i.cej.2009.10.043

[28] Bhatkhande, B.S., Pangarkar, V.G. and Beenackers, A.A.C.M. (2001) Photocatalytic degradation for environmental applications-A review. Journal of Chemical Technology and Biotechnology, 77, 102-116. doi:10.1002/jctb.532

[29] Fu, X., Zeltner, W.A. and Anderson, M.A. (1996) Applications in photocatalytic purification of air. Science, 445-461.

[30] Peral, J., Domenech, S. and Ollis, D.F. (1997) Heterogeneous photocatalysis for purification, decontamination and deodorization of air. Journal of Chemical Technology and Biotechnology, 70, 117-140. doi:10.1002/(SICI)1097-4660(199710)70:2<117::AID-JC TB746>3.0.CO;2-F

[31] Mills, A. and Le Hunte, S. (1997) An overview of semiconductor photocatalysis. Journal of Photochemistry and Photobiology A: Chemistry, 108, 1-35. doi:10.1016/S1010-6030(97)00118-4

[32] Demeestere, K., Dewulf, J. and Van Langenhove, H. (2007) Heterogeneous photocatalysis as an advanced oxidation process for the abatement of chlorinated, monocyclic aromatic and sulfurous volatile organic compounds in air: State-of-the-art. Critical Reviews in Environmental Science and Technology, 37, 489-548. doi:10.1080/10643380600966467

[33] Herrmann, J.M. (2010) Environmental photocatalysis: Perspectives for China. Science China Chemistry, 53, 1831-1843. doi:10.1007/s11426-010-4076-y

[34] Hufschmidt, D., Liu, L., Selzer, V., et al. (2004) Photocatalytic water treatment: Fundamental knowledge for its practical application. Water Science and Technology, 49, 135-140.

[35] Kikuchi, Y., Sunada, K., Iyoda, T., et al. (1997) Photocatalytic bactericidal effect of $\mathrm{TiO}_{2}$ thin films: Dynamic view of the active oxygen species responsible for the effect. Photochemistry and Photobiology A: Chemistry, 106, 51-56.

[36] Agrios, A.G. and Pichat, P. (2005) State of the art and perspectives on materials and applications of photocatalysis over $\mathrm{TiO}_{2}$. Reviews in Applied Electrochemistry, 58, 655-663. doi:10.1007/s10800-005-1627-6

[37] Demeestere, K., Dewulf, J. and Van Langenhove, H. (2007) Heterogeneous photocatalysis as an adavanced oxidation process for the abatement of chlorinated, monocyclic aromatic and sulfurous volatile organic compounds in air: State of the art. Critical reviews in Environmental Science and Technology, 37, 489-538. doi:10.1080/10643380600966467

[38] Toma, F.L., Bertrand, G., Klein, D., et al. (2004) Photocatalytic removal of nitrogen oxides via titanium dioxide. Environmental Chemistry Letters, 2, 117-121. doi:10.1007/s10311-004-0087-2

[39] Cao, L.X., Spiess, F.J., Huang, A.M., et al. (1999b) Heterogeneous photocatalytic oxidation of 1-butene on $\mathrm{SnO}_{2}$ and $\mathrm{TiO}_{2}$ films. Journal of Physical Chemistry B, 103, 2912-2917. doi:10.1021/jp983860z

[40] Benoit-Marquie, F., Wilkenhoner, U., Simon, V., et al. (2000) VOC photodegradation at the gas-solid interface of a $\mathrm{TiO}_{2}$ photocatalyst part I: 1-butanol and 1-butylamine. Journal of Photochemistry and Photobiology A: Chemistry, 132, 225-232. doi:10.1016/S1010-6030(00)00196-9 
[41] Nimlos, M.R., Wolfrum, E.J., Brewer, M.L., et al. (1996) Gas-phase heterogeneous photocatalytic oxidation of ethanol: Pathways and kinetic modeling. Environmental Science and Technology, 30, 3102-3110. doi:10.1021/es9602298

[42] Ollis, D.F. and Al-Ekabi, H. (1993) Photocatalytic purification and treatment of water and air. Science, 511-532.

[43] Hager, S., Bauer, R. and Kudielka, G. (2000) Photocatalytic oxidation of gaseous chlorinated organics over titanium oxide. Chemosphere, 41, 1219-1225. doi:10.1016/S0045-6535(99)00558-5

[44] Obee, T.N. and Brown, R.T. (1995) $\mathrm{TiO}_{2}$ photocatalysis for indoor air applications- effects of humidity and trace contaminant levels on the oxidation rates of formaldehyde, toluene, and 1,3-butadiene. Environmental Science and Technology, 29, 1223-1231. doi:10.1021/es00005a013

[45] Obee, T.N. (1996) Photooxidation of sub-parts-per-million toluene and formaldehyde levels an titania using a glass-plate reactor. Environmental Science and Technology, 30, 3578-3584. doi:10.1021/es9602713

[46] Cao, L.X., Huang, A.M., Spiess, F.J., et al. (1999a) Gasphase oxidation of 1-butene using nanoscale $\mathrm{TiO}_{2}$ photocatalysts. Journal of Catalysis, 188, 48-57. doi:10.1006/jcat.1999.2596

[47] Cao, L.X., Gao, Z., Suib, S.L., et al. (2000) Photocatalytic oxidation of toluene on nanoscale $\mathrm{TiO}_{2}$ catalysts: Studies of deactivation and regeneration. Journal of $\mathrm{Ca}$ talysis, 196, 253-261. doi:10.1006/jcat.2000.3050

[48] Pichat, P., Disdier, J., Hoang-Van, C., et al. (2000) Purification/deodorization of indoor air and gaseous effluents by $\mathrm{TiO}_{2}$ photocatalysis. Catalyst Today, 63, 363-369. doi:10.1016/S0920-5861(00)00480-6

[49] Jo, W.K. and Park, K.H. (2004) Heterogeneous photocatalysis of aromatic and chlorinated volatile organic compounds (VOCs) for non-occupational indoor air application. Chemosphere, 57, 555-565. doi:10.1016/j.chemosphere.2004.08.018

[50] Shiraishi, F., Toyoda, K. and Miyakawa, H. (2005) Decomposition of gaseous formaldehyde in a photocatalytic reactor with a parallel array of light sources-Reactor performance. Chemical Engineering Journal, 114, 145-151. doi:10.1016/j.cej.2005.09.008

[51] Blo $\beta$, S.P. and Elfenthal, L. (2007) Doped titanium dioxide as a photocatalyst forUVand visible light. Proceedings International RILEM Symposium on Photocatalysis, Environment and Construction Materials, Florence, 8-9 October 2007, 31-38.

[52] Anpo, M. and Takeuchi, M. (2003) The design and development of highly reactive titanium oxide photocatalysts operating under visible light irradiation. Journal of Catalysis, 216, 505-516. doi:10.1016/S0021-9517(02)00104-5

[53] Yamashita, H., Harada, M., Misaka, J., et al. (2002) Degradation of propanol diluted in water under visible light irradiation using metal ion-implanted titanium dioxide photocatalysts. Journal of Photochemistry and Photobiology A: Chemistry, 148, 257-261.

\section{doi:10.1016/S1010-6030(02)00051-5}

[54] Wu, J.C.S. and Chen, C.H. (2004) A visible-light response vanadium-doped titania nanocatalyst by sol-gel method. Journal of Photochemistry and Photobiology A: Chemistry, 163, 509-515. doi:10.1016/j.jphotochem.2004.02.007

[55] Fuerte, A., Hernandez-Alonso, M.D., Maira, A.J., et al. (2002) Nanosize Ti-W mixed oxides: Effect of doping level in the photocatalytic degradation of toluene using sunlight-type excitation. Journal of Catalysis, 212, 1-9. doi:10.1006/jcat.2002.3760

[56] Chapuis, Y., Kivana, D., Guy, C., et al. (2002) Photocatalytic oxidation of volatile organic compounds using fluorescent visible light. Journal of the Air \& Waste Management Association, 52, 845-854. doi:10.1080/10473289.2002.10470816

[57] Belver, C., Bellod, R., Fuerte, A., et al. (2006) Nitrogen-containing $\mathrm{TiO}_{2}$ photocatalysts: Part 1. Synthesis and solid characterization. Applied Catalysis B: Environmental, 65, 301-308.

[58] Lettmann, C., Hildenbrand, K., Kisch, H., et al. (2001) Visible light photodegradation of 4-chlorophenol with a coke containing titanium dioxide photocatalyst. Applied Catalysis B: Environmental, 32, 215-227.

[59] Asahi, R., Morikawa, T., Ohwaki, T., et al. (2001) Visible-light photocatalysis in nitrogen-doped titanium oxides. Science, 293, 269-271. doi:10.1126/science.1061051

[60] Ihara, T., Miyoshi, M., Iriyama, Y., et al. (2003) Visible-light-active titanium oxide photocatalyst realized by an oxygen-deficient structure and by nitrogen doping. Applied Catalysis B: Environmental, 42, 403-409.

[61] Miyauchi, M., Ikezawa, A., Tobimatsu, H., et al. (2004) Zeta potential and photocatalytic activity of nitrogen doped $\mathrm{TiO}_{2}$ thin films. Physical Chemistry Chemical Physics, 6, 865-870. doi:10.1039/b314692h

[62] Irokawa, Y., Morikawa, T., Aoki, K., et al. (2006) Photodegradation of toluene over $\mathrm{TiO}_{2}-\mathrm{xNx}$ under visible light irradiation. Physical Chemistry Chemical Physics, 8, 11161121. doi:10.1039/b517653k

[63] Wang, X.C., Yu, J.C., Chen, Y.L., et al. (2006) $\mathrm{ZrO}_{2^{-}}$ modified mesoporous manocrystalline $\mathrm{TiO}_{2}-\mathrm{xNx}$ as efficient visible light photocatalysts. Environmental Science and Technology, 40, 2369-2374. doi:10.1021/es052000a

[64] Belver, C., Bellod, R., Stewart, S.J., et al. (2006b) Nitrogencontaining $\mathrm{TiO}_{2}$ photocatalysts: Part 2. Photocatalytic behavior under sunlight excitation. Applied Catalysis $B$ : Environmental, 65, 309-314.

[65] Umebayashi, T., Yamaki, T., Itoh, H., et al. (2002) Band gap narrowing of titanium dioxide by sulfur doping. Applied Physics Letters, 81, 454-456. doi:10.1063/1.1493647

[66] Umebayashi, T., Yamaki, T., Itoh, H., et al. (2003) Visible Light-Induced Degradation of Methylene Blue on Sdoped $\mathrm{TiO}_{2}$. Chemistry Letters, 32, 330-331. doi:10.1246/cl.2003.330

[67] Ohno, T., Mitsui, T. and Matsumara, M. (2003) Photocatalytic activity of S-doped $\mathrm{TiO}_{2}$ photocatalyst under visible light. Chemistry Letters, 32, 364-365. 
doi:10.1246/cl.2003.364

[68] Irie, H., Watanabe, Y. and Hashimoto, K. (2003) Carbon-doped anatase $\mathrm{TiO}_{2}$ powders as a visible-light sensitive photocatalyst. Chemistry Letters, 32, 772-773. doi:10.1246/cl.2003.772

[69] Zhang, Y.H., Tang, Z.R., Fu, X.Z., et al. (2011) Nanocomposites of $\mathrm{Ag}-\mathrm{AgBr}-\mathrm{TiO}_{2}$ as a photoactive and durable catalyst for degradation of volatile organic compounds in the gas phase. Applied Catalysis B: Environmental, 106, 445-452. doi:10.1016/j.apcatb.2011.06.002

[70] Yu, H., Zhang, K. and Rossi, C. (2007) Theoretical study on photocatalytic oxidation of VOCs using nano- $\mathrm{TiO}_{2}$ photocatalyst. Photochemistry and Photobiology A: Chemistry, 188, 65-73.

[71] Hussain, M., Russo, N. and Saracco, G. (2011) Photocatalytic abatement of VOCs by novel optimized $\mathrm{TiO}_{2}$ nanoparticles. Chemical Engineering Journal, 166, 138149. doi:10.1016/j.cej.2010.10.040

[72] Herrmann, J.M. (1999) Heterogeneous photocatalysis: Fundamentals and applications to the removal of various types of aqueous pollutants. Catalyst Today, 53, 115-129. doi:10.1016/S0920-5861(99)00107-8

[73] Obee, T.N. and Hay, S.O. (1997) Effects of moisture and temperature on the photooxidation of ethylene on titania. Environmental Science and Technology, 31, 2034-2038. doi:10.1021/es960827m

[74] Noguchi, T., Fujishima, A., Sawunytama, P., et al. (1998) Photocatalytic degradation of gaseous formaldehyde using $\mathrm{TiO}_{2}$ film. Environmental Science and Technology, 32, 3831-3833. doi:10.1021/es980299+

[75] Cao, L. (1999) Gas-phase oxidation of 1-butene using nanoscale $\mathrm{TiO}_{2}$ photocatalysts. Journal of Catalysis, 188, 48-57. doi:10.1006/jcat.1999.2596

[76] Mehos, M.S. and Turchi, C.S. (1993) Field testing solar photocatalytic detoxification on TCE-contaminated groundwater. Environmental Progress, 12, 194-199. doi:10.1002/ep.670120308

[77] Herrmann, J.M., Peruchon, L., Puzenat, E., et al. (2007) Photocatalysis: From fundamentals to self-cleaning glass application. Proceedings International RILEM Symposium on Photocatalysis, Environment and Construction Materials, Florence, 8-9 October 2007, 41-48.

[78] Egerton, T.A. and King, C.J. (1979) The influence of light intensity on photoactivity in titanium dioxide pigmented systems. Journal of the Oil and Colour Chemists Association, 62, 386-391.

[79] Herrmann, J.M. (2006) Water Treatment by Heterogeneous Photocatalysis. Kirk-Othmer Encyclopedia of Chemical Technology, 19, 73-106.

[80] Herrmann, J.M. (2006) From catalysis by metals to bifunctional photo catalysis. Topics in Catalysis, 33, 421431.

[81] Luo, Y. and Ollis, D.F. (1996) Heterogeneous photocatalytic oxidation of trichloroethylene and toluene mixtures in air: Kinetic promotion and inhibition, time-dependent catalyst activity. Journal of Catalysis, 163, 1-11. doi:10.1006/jcat.1996.0299

[82] Beeldens, A. (2007) Air purification by road materials: Results of the test project in Antwerp. Proceedings International RILEM Symposium on Photocatalysis, Environment and Construction Materials, Florence, 8-9 October 2007, 187-194.

[83] Ao, C.H., Lee, S.C., Mak, C.L., et al. (2003) Photodegradation of volatile organic compounds (VOCs) and NO for indoor air purification using $\mathrm{TiO}_{2}$ : Promotion versus inhibition effect of NO. Applied Catalysis B: Environmental, 42, 119-129.

[84] Ao, C.H. and Lee, S.C. (2005) Indoor air purification by photocatalyst $\mathrm{TiO}_{2}$ immobilized on an activated carbon filter installed in an air cleaner. Chemical Engineering Science, 60, 103-109. doi:10.1016/j.ces.2004.01.073

[85] O’Malley, A. and Hodnett, B.K. (1999) The influence of volatile organic compound structure on conditions required for total oxidation. Catalysis Today, 54, 31-38. doi:10.1016/S0920-5861(99)00166-2

[86] Lin, H., Huang, C.P, Li, W., et al. (2006) Size dependency of nanocrystalline $\mathrm{TiO}_{2}$ on its optical property and photocatalytic reactivity exemplified by 2-chlorophenol. Applied Catalysis B: Environmental, 68, 1-11. doi:10.1016/j.apcatb.2006.07.018

[87] Bakardjieva, S., Stengl, V., Szatmary, L., et al. (2006) Transformation of brookite-type $\mathrm{TiO}_{2}$ nanocrystals to rutile: Correlation between microstructure and photoactivity. Materials Chemistry, 16, 1709-1716. doi:10.1039/b514632a

[88] Watson, S.S., Beydoun, D., Scott, J.A., et al. (2003) The effect of preparation method on the photoactivity of crystalline titanium dioxide particles. Chemical Engineering Journal, 95, 213-220. doi:10.1016/S1385-8947(03)00107-4

[89] Bacsa, R.R. and Kiwi, J. (1998) Effect of rutile phase on the photocatalytic properties of nanocrystalline titania during the degradation of p-coumaric acid. Applied $\mathrm{Ca}$ talysis B: Environmental, 16, 19-29. doi:10.1016/S0926-3373(97)00058-1

[90] Testino, A., Bellobono, I.R., Buscaglia, V., et al. (2007) Optimizing the photocatalytic properties of hydrothermal $\mathrm{TiO}_{2}$ by the control of phase composition and particle morphology. Journal of the American Chemical Society, 129, 3564-3575. doi:10.1021/ja067050+

[91] Porkodi, K. and Arokiamary, S.D. (2007) Synthesis and spectroscopic characterization of nanostructured anatase titania: A photocatalyst. Materials Characterization, 58, 495-503. doi:10.1016/j.matchar.2006.04.019

[92] Zoua, L., Luo, Y.G., Hooper M., et al. (2006) Removal of VOCs by photocatalysis process using adsorption enhanced $\mathrm{TiO}_{2}-\mathrm{SiO}_{2}$ catalyst. Chemical Engineering and Processing, 45, 959-964. doi:10.1016/j.cep.2006.01.014 